\title{
Concentrações hormonais e desenvolvimento folicular de vacas leiteiras em hipertermia sazonal e aguda
}

[Hormone concentration and follicular development in dairy cows under seasonal and acute hyperthermia]

\author{
B.J. Lew ${ }^{1,2}$, R. Meidan ${ }^{2}$, D. Wolfenson ${ }^{2}$ \\ ${ }^{1}$ Faculdade de Ciências Agrárias e Veterinárias, UNESP \\ Via de Acesso Paulo Donato Castelani, s/n \\ 14884-900 - Jaboticabal - SP \\ ${ }^{2}$ Faculty of Agriculture - The Hebrew University of Jerusalem - Rehovot, Israel
}

\begin{abstract}
RESUMO
Avaliaram-se as concentrações hormonais e os parâmetros de desenvolvimento folicular de vacas leiteiras expostas ao calor sazonal e agudo. Dividiram-se os animais em quatro grupos: verão $(n=5)$, outono $(n=5)$, inverno com hipertermia aguda (grupo câmara climática, $(C C), n=5)$ e inverno $(n=9)$. Os animais foram abatidos no sétimo dia após a ovulação, e os parâmetros de desenvolvimento folicular avaliados. $\mathrm{O}$ líquido folicular do maior folículo foi aspirado e armazenado para posterior análise de hormônios esteróides e inibina. $\mathrm{O}$ número de células da granulosa vivas no verão e no outono foi 40 e $45 \%$ respectivamente, menor que no inverno $(\mathrm{P}<0,05)$. A concentração de estradiol $\left(\mathrm{E}_{2}\right)$ no inverno foi $62 \%$ maior que no outono $(\mathrm{P}<0,05)$ e $34 \%$ superior ao grupo verão $(\mathrm{P}<0,06)$. Houve um aumento na quantidade de androstenediona no verão em relação aos grupos inverno $(\mathrm{P}<0,08)$ e outono $(\mathrm{P}<0,05)$. A concentração de inibina foi maior no inverno do que no verão e $\mathrm{CC}(\mathrm{P}<0,05)$. A exposição ao calor sazonal e agudo modificou os parâmetros de desenvolvimento do folículo e as concentrações hormonais no líquido folicular, podendo explicar em parte a queda nas taxas de concepção no verão.
\end{abstract}

Palavras-chave: folículo, estresse térmico, esteróide, inibina, reprodução

\begin{abstract}
The present study evaluated the seasonal and acute heat stress on follicular development and steroid and inhibin concentrations in follicular fluid, in bovine dominant follicle. Cows were distributed into four treatments: summer ( $n=5)$, autumn $(n=5)$, animals heat stressed during the winter $(n=5)$ and winter $(n=9)$. On day 7 of the estrous cycle, animals were slaughtered and parameters related to follicle development were evaluated. The follicular fluid (FF) was aspirated and stored for further hormonal analysis. During the summer, the number of viable granulosa cells was $40 \%$ lower than during the winter, and there was a $45 \%$ decrease in this parameter during the autumn $(P<0.05)$. In the winter, estradiol concentration was $62 \%$ higher than during the autumn $(P<0.05)$ and $42 \%$ higher than during the summer $(P<0.06)$. There was an increase in androstenedione concentration in summer group, when compared to winter $(P<0.08)$ and autumn $(P<0.05)$ groups. Inhibin concentration was higher in winter groups than summer and winter heat stressed groups $(P<0.05)$. Seasonal and acute heat stress altered developmental parameters in dominant follicle and hormonal concentration in follicular fluid, those effects can partially explain the decrease in conception rates during summer.
\end{abstract}

Keywords: follicle, heat stress, steroids, inhibin, reproduction

Recebido em 26 de abril de 2005

Aceito em 3 de maio de 2006

E-mail: betlew@fcav.unesp.br 


\section{INTRODUÇÃO}

Um dos principais fatores de baixa fertilidade em vacas leiteiras é o estresse térmico. Esse é um problema que acarreta perdas econômicas graves e afeta $60 \%$ do rebanho mundial (Wolfenson et al., 2000). As taxas de concepção caem de 40 a $60 \%$ nos meses de temperaturas mais amenas do ano e para 10 a $20 \%$ nos meses quentes (Cavestany et al., 1985). A característica predominante da subfertilidade no verão é a sua natureza multifatorial, já que a hipertermia altera diretamente e debilita as funções celulares de diversos tecidos reprodutivos. Além disso, a exposição de bovinos ao calor induz respostas indiretas como redistribuição de fluxo sangüíneo através dos órgãos, redução no consumo alimentar, alcalose respiratória, entre outros, que podem ter um impacto no sistema reprodutor (Wolfenson et al., 2000). Tradicionalmente, a queda na fertilidade é associada aos meses mais quentes do ano, no entanto, a mesma continua relativamente baixa nos meses de outono quando comparada às médias de inverno (Wolfenson et al., 1997).

O folículo pré-ovulatório é um componente chave do sistema reprodutor e um efeito negativo do calor que em sua função normal pode prejudicar outros eventos ligados à reprodução, como secreção de gonadotropinas (Gilad et al., 1992), subseqüente desenvolvimento do corpo lúteo (Wolfenson et al., 1993) e do embrião (Putney et al., 1989), resultando em baixa fertilidade. Estudos indicam que o folículo dominante é sensível à exposição ao calor (Wolfenson et al., 1995) e a observação ultrasonografia mostrou que o estresse térmico altera o desenvolvimento e a dominância folicular no ciclo estral (Badinga et al., 1993).

Objetivou-se avaliar a concentração hormonal no líquido folicular (LF) e parâmetros de desenvolvimento folicular de vacas leiteiras expostas ao calor em diferentes intensidades e duração.

\section{MATERIAL E MÉTODOS}

Utilizaram-se vacas leiteiras da raça Holandesa variedade Israelense, com ciclo regular, em período final de lactação, produzindo $10-15 \mathrm{~kg}$ de leite por dia. O manejo utilizado foi uniforme ao longo do ano, e os animais receberam ração completa contendo $16,5 \%$ de proteína bruta, $1,70 \mathrm{Mcal} / \mathrm{kg}$ de energia metabolizável na matéria seca e $32 \%$ de fibra em detergente neutro (FDN).

Os animais foram divididos em quatro grupos: verão $(n=5)$, outono $(n=5)$, inverno $(n=9$, grupocontrole) e grupo câmara climática (CC) que compreendeu animais no inverno, expostos ao estresse térmico durante três dias, nos dias 3 a 5 do ciclo estral $(n=5)$.

O método de sincronização de cio utilizado foi o controled intravaginal drug releasing (CIDR $)^{1}$ que consistia em $1,9 \mathrm{~g}$ de progesterona na forma natural $\left(\mathrm{P}_{4}\right)$ introduzidos na vagina durante nove dias e injeção intramuscular de análogo de prostaglandina $\left(\mathrm{PGF}_{2 \alpha}\right), 2,5 \mathrm{ml}$ na concentração de $0,236 \mathrm{~g} / \mathrm{ml}$ (Estrumate $^{2}$ ) dois dias antes da retirada do CIDR. Os animais foram abatidos sete dias após a apresentação de cio.

Os ovários do grupo verão foram coletados no mês de setembro, quando a média máxima diária de THI (temperature humidity index) atingiu 79,9. Médias de THI acima de 72 são consideradas estressantes para vacas leiteiras (Ingraham et al., 1974). Durante julho e agosto, anteriormente à coleta dos ovários, os valores máximos de THI foram de 81,4 e 81,5 respectivamente.

Nos experimentos de outono, coletaram-se os ovários no mês de novembro a fim de identificar possíveis efeitos residuais do calor de verão. Neste mês, as temperaturas estavam mais amenas, com THI de 70,4, tendo atingido 79,9 e 76,6 nos meses de setembro e outubro, respectivamente. $\mathrm{O}$ experimento de outono foi realizado para verificação de possíveis efeitos do calor durante essas fases de desenvolvimento dos folículos.

No inverno, abateram-se os animais em fevereiro, quando a THI máxima foi de 65,4.

Os animais do grupo CC foram expostos ao calor numa câmara climática entre os dias 3 e 5 do ciclo estral. Para eliminar possíveis efeitos de confinamento, os animais foram colocados no local para adaptação uma semana antes do experimento. Durante 12 horas, os animais eram

1 , Eazi Breed, Hamilton, Nova Zelândia

${ }^{2}$, Coopers Berkhmasted, Inglaterra 
expostos à temperatura de $36^{\circ} \mathrm{C}$ e umidade relativa de $60 \%(\mathrm{THI}=88,3)$. As temperaturas corporais desses animais aumentaram gradativamente até atingir aproximadamente $40,5^{\circ} \mathrm{C}$. Caso houvesse aumento nessa temperatura, o animal era resfriado com spray de água.

Após o abate, os ovários foram armazenados em gelo até a chegada ao laboratório. Os diâmetros do maior folículo foram medidos, LF aspirado, medido o volume folicular e armazenados a $20^{\circ} \mathrm{C}$ para posteriores análises. $\mathrm{Na}$ presença de dois folículos maiores que $10 \mathrm{~mm}$, a dominância foi verificada por meio de contagem do número de células da granulosa e determinação rápida de estradiol no LF com ${ }^{125}$ I-estradiol $k i t^{3}$.

As células da teca e da granulosa foram isoladas de acordo com Meidan (1990), e a viabilidade das mesmas foi verificada pela coloração com trypan blue.

As concentrações de 17ß-estradiol $\left(\mathrm{E}_{2}\right)$, androstenediona, progesterona $\left(\mathrm{P}_{4}\right)$ e inibina no $\mathrm{LF}$ foram realizadas com a técnica de radioimunoensaio. LF foi diluído de acordo com a sensibilidade do teste, e o paralelismo das amostras diluídas com a curva padrão validada. Para $\mathrm{E}_{2}$, androstenediona, $\mathrm{P}_{4}$ e inibina obtiveramse coeficientes de variação intra análises de $13,3 \%, 9,9 \%, 4,6 \%$, e $5,0 \%$ e entre análises $13,9 \%, 13,2 \%, 8,6 \%$ e $14,0 \%$ respectivamente.

Para análise de variância, utilizou-se o procedimento de modelos lineares gerais (GLM) (User's..., 2000). Aplicou-se o teste de análise de variância (ANOVA), para avaliação dos efeitos de estação do ano nas características foliculares e concentrações hormonais no LF. As concentrações de hormônios foram normalizadas de acordo com a quantidade de células da granulosa vivas. Mediram-se as diferenças entre as médias nas estações do ano pelo teste de Tukey, e os valores $\mathrm{P}$ corrigidos pelo método de Bonferroni.

\section{RESULTADOS}

Os diâmetros dos maiores folículos não diferiram significativamente entre os grupos. $\mathrm{O}$ volume do $\mathrm{LF}$ do grupo $\mathrm{CC}$ foi menor do que no grupo inverno $(\mathrm{P}<0,05)$. Não houve diferença significativa entre os três outros grupos em termos de volume de LF (Tab.1).

O número total de células da granulosa não diferiu nos folículos dos quatro grupos. A viabilidade (relação entre o número de células vivas e número total de células encontrado) das células da granulosa diminuiu no grupo verão e no grupo outono em relação ao grupo inverno $(\mathrm{P}<0,05)$ (Tab. 1). A porcentagem de células vivas no grupo $\mathrm{CC}$ não diferiu dos grupos inverno, verão e outono; esses dois últimos grupos não diferiram entre si para esse parâmetro (Tab. 1). Não houve diferença significativa no número de células da teca entre as estações, a qual se manteve superior a 95\% (dados não apresentados).

A concentração média de $\mathrm{E}_{2}$ no grupo inverno foi maior que no grupo outono $(\mathrm{P}<0,05)$ e que no grupo verão $(\mathrm{P}<0,06)$. Não houve diferença significativa de $\mathrm{E}_{2}$ no $\mathrm{FF}$ entre o grupo $\mathrm{CC}$ e os outros grupos (Tab. 2).

A concentração média de androstenediona no grupo inverno foi menor que a verificada no grupo verão $(\mathrm{P}<0,08)$. No grupo outono, essa diferença foi ainda mais marcante $(\mathrm{P}<0,05)$. Não houve diferenças significativas entre as concentrações médias de androstenediona no grupo CC e nos outros (Tab. 2).

As concentrações de $\mathrm{P}_{4}$ no $\mathrm{LF}$ não diferiram entre os grupos (Tab. 2).

Houve diminuição nas concentrações de inibina no LF nos grupos verão e $\mathrm{CC}$ quando comparadas ao grupo inverno $(\mathrm{P}<0,05)$. As concentrações de inibina no LF do grupo outono não diferiram estatisticamente dos outros três grupos (Tab. 2).

\footnotetext{
${ }^{3}$ Diagnostic products Los Angeles, CA)
} 
Tabela 1. Características do maior folículo no $7^{\circ}$ dia do ciclo estral, durante as estações do ano

\begin{tabular}{lllll}
\hline & Verão & Outono & Inverno & CC \\
\hline No. de animais & 5 & 5 & 9 & 5 \\
Diâmetro folicular $(\mathrm{mm})$ & $13,8 \pm 1,2$ & $12,0 \pm 1,2$ & $13,3 \pm 0,9$ & $12,4 \pm 1,2$ \\
Volume do fluido $(\mathrm{cc})$ & $1,2 \pm 0,2 \mathrm{ab}$ & $1,3 \pm 0,2 \mathrm{ab}$ & $1,5 \pm 0,2 \mathrm{a}$ & $1,0 \pm 0,2 \mathrm{~b}$ \\
No. cel. granulosa $\left(10^{6}\right)$ & $7,6 \pm 1,2$ & $6,6 \pm 1,1$ & $7,0 \pm 0,8$ & $6,4 \pm 1,1$ \\
Viabilidade $(\%)$ & $23,2 \pm 7,7 \mathrm{~b}$ & $21,0 \pm 6,9 \mathrm{~b}$ & $38,3 \pm 4,9 \mathrm{a}$ & $32,3 \pm 6,9 \mathrm{ab}$ \\
\hline
\end{tabular}

Valores seguidos por letras distintas na linha diferem entre si, pelo teste de Tukey $(\mathrm{P}<0,05)$.

$\mathrm{CC}$ = grupo câmara climática, consistindo de animais nos meses de inverno, estressados artificialmente entre os dias 3 e 5 do ciclo estral.

Tabela 2. Concentrações de esteróides e inibina no líquido folicular dos maiores folículos, no $7^{\circ}$ dia do ciclo estral, durante as estações do ano

\begin{tabular}{lllll}
\hline Hormônio & Verão & Outono & Inverno & CC \\
\hline Estradiol $17 \beta(\mathrm{ng} / \mathrm{ml})$ & $72,4 \pm 18,7 \mathrm{a}^{*}$ & $41,4 \pm 18,7 \mathrm{~b}$ & $110,8 \pm 15,8 \mathrm{a}$ & $78,2 \pm 19,1 \mathrm{ab}$ \\
Androstenediona $\mathrm{ng} / \mathrm{ml})$ & $2,2 \pm 0,7^{\mathrm{a}}$ & $0,5 \pm 0,6 \mathrm{~b}$ & $0,8 \pm 0,6 \mathrm{~b}^{+}$ & $1,5 \pm 0,6 \mathrm{ab}$ \\
Inibina $(\mu \mathrm{g} / \mathrm{ml})$ & $17,1 \pm 3,9 \mathrm{~b}$ & $25,0 \pm 3,9 \mathrm{ab}$ & $28,0 \pm 3,1 \mathrm{a}$ & $16,3 \pm 3,9 \mathrm{~b}$ \\
Progesterona $(\mathrm{ng} / \mathrm{ml})$ & $13,1 \pm 1,9$ & $10,4 \pm 1,7$ & $10,9 \pm 1,1$ & $8,9 \pm 1,4$ \\
\hline
\end{tabular}

Valores seguidos por letras distintas na linha diferem entre si, pelo teste de Tukey $\left(\mathrm{P}<0,05,{ }^{*} \mathrm{P}<0,06,{ }^{+} \mathrm{P}<0,08\right)$.

$\mathrm{CC}=$ grupo câmara climática, consistindo de animais nos meses de inverno, estressados artificialmente entre os dias 3 e 5 do ciclo estral.

\section{DISCUSSÃO}

As condições de manejo e alimentação mantiveram-se estáveis e consistentes, portanto, as causas prováveis dos resultados encontrados foram as diferenças de condições climáticas entre as estações do ano.

Os folículos de animais do grupo verão foram expostos ao calor durante toda a fase antral do desenvolvimento folicular, com duração aproximada de dois ciclos estrais (Wolfenson et al., 2000). Por outro lado, os folículos obtidos no outono, quando as condições climáticas são mais amenas, foram expostos ao calor numa fase anterior a esse desenvolvimento. Vale ressaltar que um folículo ovariano requer aproximadamente 45 dias para crescer de $0,1 \mathrm{~mm}$ até atingir o seu tamanho de dominância de 9,0 mm (Wolfenson et al., 2000).

Encontrou-se uma diminuição de mais de $40 \%$ na quantidade de células da granulosa vivas nos folículos dos animais dos grupos verão e outono. A curta exposição ao calor (grupo $\mathrm{CC}$ ) não causou queda no número de células da granulosa vivas em relação ao grupo-controle, inverno. Lew et al. (1993) verificaram que incubação das células da teca e da granulosa a $40,5^{\circ} \mathrm{C}$, durante 18 horas, não causou a morte das células. As células dos mamíferos são capazes de sobreviver a temperaturas de $40^{\circ} \mathrm{C}$, durante um período ininterrupto de 3 horas, no entanto, incubação por um tempo mais longo e à temperatura de $42^{\circ} \mathrm{C}$, pode lesar as células, chegando a causar a morte celular (Coakley, 1987).

A queda no número de células da granulosa vivas no verão e no outono sugere que, em alguma etapa do crescimento folicular, os animais passaram por uma forte hipertermia, na qual a temperatura corporal ultrapassou os níveis suportáveis $\left(40,5^{\circ} \mathrm{C}\right)$, causando assim danos irreversíveis às células da granulosa. $\mathrm{O}$ tempo de exposição dos animais ao calor também influi na viabilidade das células (Coakley, 1987).

A média geral de células da granulosa encontrada $\left(7 \times 10^{6}\right)$ coincide com trabalho realizado por Ireland e Roche (1982), que observaram $11 \times 10^{6}$ células da granulosa, em folículos retirados de novilhas no sétimo dia do ciclo estral. Entre os dias 5-8 do ciclo, o folículo se encontra no pico da atividade estrogênica, com tendência à queda dessa atividade no oitavo dia do ciclo (Badinga et al., 1993). Portanto, é possível que no dia da análise (sétimo dia) os folículos já apresentassem um início da queda da atividade estrogênica. 
Independente da estação do ano, o percentual de células da teca vivas se manteve alto ( $>95 \%)$. As razões para a alta viabilidade de células da teca não são totalmente claras, no entanto, uma situação similar a essa é observada nos folículos pré-ovulatórios (Meidan ${ }^{4}, 1993$, comunicação pessoal). É possível que uma das razões seja o grande volume de fluxo sanguíneo para essas células. Os vasos sangüíneos estão depositados diretamente dentro da membrana de células da teca, ao contrário das células da granulosa que estão envoltas pela membrana basal, portanto, as primeiras são mais bem nutridas, levando a uma provável maior resistência dessas em relação às células da granulosa.

O diâmetro do maior folículo não sofreu influências dos tratamentos, e a média dos mesmos foi de $13 \mathrm{~mm}$ no dia do abate. Em trabalhos anteriores, encontrou-se o mesmo resultado em folículos dominantes retirados de novilhas no sétimo dia do ciclo $(13 \mathrm{~mm})$ (Ireland e Roche, 1982). Savio et al. (1988) observaram que o primeiro folículo dominante, em novilhas, atinge o diâmetro máximo $(15,5 \mathrm{~mm})$ no dia 6,3 do ciclo estral. Badinga et al. (1993) não encontraram diferença entre os diâmetros de folículos dominantes retirados de vacas leiteiras no início (julho) e no fim (setembro) do verão. No mesmo trabalho, animais expostos ao calor durante os sete primeiros dias do ciclo estral apresentaram uma diminuição no volume do LF em relação aos animais que se mantiveram na sombra.

Neste trabalho, houve uma queda similar no volume do LF em animais do grupo $\mathrm{CC}$, apesar de esses animais terem sido expostos ao calor por somente três dias. Parece que o tipo de exposição (aguda), sua intensidade (temperatura corporal de aproximadamente $40,3^{\circ} \mathrm{C}$ ) e a fase da mesma são os fatores que alteraram o volume acumulado do LF. Considerando que a atividade folicular é bastante elevada nas fases finais de desenvolvimento, há uma lógica no fato de que justamente esse tipo de exposição leve à depressão da atividade e cause uma queda no volume do LF acumulado.

\footnotetext{
4 Prof. Dra. Rina Meidan, The Hebrew University of Jerusalem, Faculty of Agriculture, Department of Animal Science, Rehovot, Israel.
}

Dano em qualquer etapa do processo de esteroidogenese pode modificar a produção de $\mathrm{E}_{2}$. A esteroidogenese é um processo que envolve as células da teca e da granulosa, além das gonadotropinas - LH e FSH (Richards, 1980). As células dos folículos antrais são capazes de produzir pregnenolona a partir de colesterol e transformá-la em $\mathrm{P}_{4}$ (Rodgers et al., 1986). $\mathrm{A}_{4}$ é utilizada como precursor para as células da teca sintetizarem andrógenos. Nas células da granulosa é sintetizada a enzima aromatase, responsável pela transformação de andrógenos em estradiol. A atividade aromática é um processo que ocorre nas células da granulosa no entanto, é indispensável a produção de androstenediona pelas células da teca para esse processo (Fortune et al., 1988).

A concentração de $E_{2}$ varia nos diferentes dias do ciclo estral. Após o pico de $\mathrm{E}_{2}$ um dia antes da ovulação, é encontrado mais um pico de $E_{2}$, dessa vez menor do que o anterior, no início da fase lútea, causada pela produção de $E_{2}$ nas células do primeiro folículo dominante (de primeira onda), quando a concentração de $\mathrm{P}_{4}$ nesse folículo ainda é baixa (Ireland e Roche, 1982).

A concentração de $E_{2}$ média no $\mathrm{FF}$ do grupo inverno foi de $110,8 \pm 15,8 \mathrm{ng} / \mathrm{ml}$ similares às relatadas por Ireland e Roche (1982), em folículos dominantes, estrogenicamente ativos, no sétimo dia do ciclo estral $(141 \pm 35 \mathrm{ng} / \mathrm{ml})$. Martin et al. (1990) encontraram concentrações maiores no folículo dominante recolhidos no sexto dia do ciclo $(400 \pm 100 \mathrm{ng} / \mathrm{ml})$. É possível que a diferença nas concentrações hormonais entre os trabalhos tenha sido causada por diferenças no tamanho absoluto dos folículos entre os dias 6 e 7 do ciclo estral, que deveriam ser interpretados nos cálculos da concentração pelo volume do líquido.

Os folículos das vacas dos grupos verão e outono apresentaram concentração menor de $\mathrm{E}_{2}$ no FF do que as do grupo inverno. A queda mais drástica entre os grupos ocorreu no outono (73\%). A diminuição nessas concentrações pode ter sido causada por diferentes fatores. A menor quantidade de células da granulosa viáveis nesses folículos pode explicar em parte essa queda. 
Além disso, no FF do grupo verão encontrou-se uma quantidade maior de androstenediona do que nos grupos inverno e outono. Esses dados sugerem que no grupo verão as células da granulosa perderam a capacidade de utilizar eficientemente a androstenediona para produção de $E_{2}$, ou ainda a alta temperatura diminuiu ou inativou a aromatase, enquanto no outono, as próprias células da teca podem ter perdido a capacidade em parte, de produção de androstenediona, causando, assim, um problema de falta de precursor para células da granulosa sintetizaram $\mathrm{E}_{2}$. Por sua vez, as pequenas concentrações de androstenediona no inverno sugerem uma situação na qual as células da granulosa aproveitaram com eficiência os andrógenos como precursores para a atividade aromática.

Os resultados sugerem a existência de um efeito residual do calor sobre a capacidade das células da teca em produzir androstenediona. Esse efeito é representado pelo grupo outono. É possível que isso esteja ligado ao fato de as células da teca diferenciarem mais cedo que as células da granulosa e que, já nos folículos primários, exista a produção de androstenediona, enquanto a produção de $E_{2}$ está ligada diretamente a folículos mais desenvolvidos (McNatty et al., 1984). Badinga et al. (1993), também, encontraram uma baixa concentração de $E_{2}$ no líquido folicular de animais no final do verão.

A reação dos folículos pertencentes ao grupo CC foi similar ao grupo verão, porém em menor intensidade. Esse fato pode ser explicado pelo tempo de exposição dos animais ao calor. Além disso, os mesmos retornavam à temperatura normotérmica à noite (condições de inverno). Ao contrário, vacas em lactação no verão apresentam grande dificuldade em dissipar o calor corporal durante a noite (Wolfenson et al., 2000). Pode-se deduzir, portanto, que o estresse térmico provocado pelo calor no verão é capaz de causar danos de maior intensidade aos animais que a exposição ao calor agudo de curta duração. No entanto, a reação dos animais ao calor, mesmo quando de curta duração, mostra a sensibilidade do folículo dominante durante $o$ seu crescimento e desenvolvimento, principalmente, em relação à produção de $E_{2}$ pelas células da granulosa.
A inibina é um hormônio glicoprotéico, constituído por duas subunidades: $\alpha$ e $\beta$, ligadas entre si por pontes dissulfídicas. Sua função é a de inibir a produção hipofisária de FSH. A origem da inibina em vacas não prenhes são as células da granulosa (Findlay et al., 1991). Existem vários tipos de inibina, entre elas a $56 \mathrm{Kd}$, encontrada em grandes quantidades no LF de bovinos. Após a produção, a inibina $56 \mathrm{Kd}$ é transformada em inibina $32 \mathrm{Kd}$, sua forma biologicamente ativa.

Neste trabalho, encontrou-se queda na concentração de inibina no FF de animais no verão e CC quando comparados ao grupocontrole inverno. Nos folículos de animais no outono, a quantidade do hormônio detectada foi similar ao grupo inverno. Esses resultados vêm reforçar a hipótese de que as células da granulosa dos folículos no outono têm atividade regular, enquanto o calor do verão e da CC causou danos nessa atividade.

A capacidade das células da granulosa em produzir $\mathrm{E}_{2}$ é diretamente proporcional à capacidade de sintetizarem inibina (Ying et al., 1986). Os estrógenos não são indispensáveis à produção de inibina, no entanto, podem estimular a sua produção (Ying et al., 1988). A maioria dos fatores envolvidos na produção de $E_{2}$, como hormônios e compostos intracelulares, influenciam a produção de inibina, sendo o FSH o principal hormônio envolvido (Ying et al., 1986). Gilad et al. (1992) encontraram uma queda nas concentrações de FSH no plasma na fase folicular do ciclo estral de vacas em lactação expostas ao calor no verão. Os dados sugerem que uma das causas para a queda na concentração de inibina no LF seja a diminuição na quantidade de FSH liberada pela hipófise.

Estradiol e inibina agem em sinergismo (Ying et al., 1986), conservando a dominância do folículo e inibindo o desenvolvimento de folículos adicionais pela depressão da liberação de FSH hipofisário, indispensável para o surgimento de uma nova onda folicular (Ying et al., 1988). A queda nos níveis de inibina e $\mathrm{E}_{2}$ no $\mathrm{FF}$ de vacas em condições de estresse térmico pode danificar a dominância do folículo pré-ovulatório. Wolfenson et al. (1993) encontraram queda na dominância do maior folículo ovariano no verão, por diferentes fatores, entre eles a presença 
simultânea de mais de um folículo de tamanho grande.

Esses resultados sugerem que alterações na qualidade do folículo dominante no verão e outono podem explicar em parte a queda nas taxas de concepção de animais expostos ao calor nos meses de verão e demonstram um efeito residual desses prejuízos nos meses de outono.

\section{AGRADECIMENTOS}

As zootecnistas Cíntia Maria Battiston Loureiro e Eneida de Oliveira Almeida pela revisão ortográfica do trabalho.

\section{REFERÊNCIAS BIBLIOGRÁFICAS}

BADINGA, L.; THATCHER, W.W.; DIAZ, T., et al. Effect ofe environmental heat stress on follicular development and steroidogenesis in lactating Holstein cows. Theriogenology, v.39, p.797-810, 1993.

CAVESTANY, D.; EL-WHISKY, A.B.; FOOTE, R.H. Effect of season and high environmental temperature on fertility of Holstein cattle. J. Dairy Sci., v.68, p.1474-1478, 1985.

COAKLEY, W.T. Hyperthermia effects on the cytoskeleton and on cell morphology. In: BOWLER, K.; FULLER B.J. (Ed.), Temperature and animal cells. Soc. Exp.. Biol., p.187221, 1987.

FINDLAY, J.K.; CLARKE, U.J.; LUCK, M.R. et al. Peripheral and intragonadal actions of inhibin-related peptides. J. Reprod. Fert., v.43, p.139-150, 1991.

FORTUNE, J.E.; SIROIS, J.; QUIRK, S.M. The growth and differentiation of ovarian follicles during the bovine estrous cycle. Theriogenology. v.29, p.95-109, 1988.

GILAD, E.; MEIDAN, R.; BERMAN, A. et al. Tonic and GnRH-induced plasma concentrations of LH and FSH during acute or seasonal heat stress in dairy cows. INTERNATIONAL CONGRESS ANIMAL REPRODUCTION. 12., 1992. Netherlands, 1992. p.2054 2056.

INGRAHAM，R.H.; GILLETE，D.D.; WAGNER，W.C. Relationship of temperature and humidity to conception rate of Holstein cow in subtropical climate. J. Dairy Sci., v.57, p.476-872, 1974.

IRELAND, J.J.; ROCHE, J.F. Development of antral follicles in cattle after prostaglandin-induced luteolysis: changes in serum hormones, steroid in follicular fluid, and gonadotropin receptors. Endocrinology, v.111, p.2077-2086, 1982.

LEW, B.J.; WOLFENSON, D.; MEIDAN, R. Heat stress affects steroid content of follicular fluid and steroid production by granulosa and theca cells in the bovine dominant follicle. In: ANNUAL MEETING OF THE ISRAEL ENDOCRINE SOCIETY; Tel-Aviv, 21, 1993. (Abstr)

MARTIN, T.L.; FOGWELL, R.L.; IRELAND, J.J. Concentrations of inhibins and steroids in follicular fluid during development of dominant follicles in heifers. Biol. Reprod., v.44, p.693-700, 1991.

McNATTY, K.P.; HEATH, D.; HANDERSON, K.M. et al. Some aspects of Thecal and Granulosa cells function in the bovine ovary. J. Reprod. Fert., v.72, p.39-53, 1984.

MEIDAN, R.; GIRSH, E.; BLOOM, O. et al. In vitro differentiation of bovine Theca and Granulosa cells into small and large luteal-like cells: morphological and functions characteristics. Biol. Reprod., v.43, p.913-921, 1990.

PUTNEY, D.J.; MULLINS, S.; THATCHER, W.W. et al. Embryonic development in supervulated dairy cattle exposed to elevated ambient temperatures between the onset of oestrus and insemination. Anim. Reprod. Sci., v.19, p.37-51, 1989.

RICHARDS, J.S. Maturation of ovarian follicles: actions and interactions of pituitary and ovarian hormones on follicular cell differentiation. Physiol. Rev., v.60, p.51-89, 1980.

RODGERS, R.J.; RODGERS, H.F.; HALL, P.F.; et al. Imunolocalization of cholesterol side-chain-clevage cytochrome P450 and $17 \alpha$ hydroxylase cytochrome p450 in bovine ovarian follicles. J. Reprod. Fert., v.78, p.627-638, 1986.

SAVIO, J.D.; KEENAN, L.; BOLAND, M.P. et al. Patern of growth of dominant follicles during the oestrous cycle of Reifers. J. Reprod. Fert. v.83, p.663-671, 1988.

USER'S guide: statistics. Version 8. Cary, NC: SAS Institute, 2000 .

WOLFENSON, D.; LEW, B.J.; THATCHER, W.W. et al. Seasonal and acute heat stress effects on steroid production by dominant follicles in cow. Anim Reprod Sci., v.47, p.9-19, 1997.

WOLFENSON, D.; LUFT, O.; BERMAN, A. et al. Effects of season, incubation temperature and cell age on progesterone and prostaglandin F production in bovine luteal cells. Anim. Reprod. Sci., v.32, p.27-40, 1993.

WOLFENSON, D.; ROTH, Z.; MEIDAN, R. Impaired reproduction in heat-stressed cattle: basic and applied aspects. Anim. Reprod Sci., v. 60-61, p.535-547, 2000.

WOLFENSON, D.; THATCHER, W.W.; BADINGA, L.; et al. The effect of heat stress on follicular development during the estrous cycle dairy cattle. Biol. Reprod., v.52, p.11061113,1995 .

YING, S.-Y. Inhibins, activins and follistatins: gonadal proteins modulating the secretion of follicle-stimulating hormone. Endocr. Rev., v.9, p.267-293, 1988.

YING, S.-Y.; CZVIK, J.; BECKER, A.; et al. Secretion of follicle stimulating hormone and production of inhibin are reciprocally related. Proc. Natl. Acad. Sci., v.84, p.46314637, 1986 . 